\title{
Working memory deficits in schizophrenia are associated with the rs34884856 variant and expression levels of the NR4A2 gene in a sample Mexican population: a case control study
}

Elizabeth Ruiz-Sánchez ${ }^{1}$, Janet Jiménez-Genchi ${ }^{2}$, Yessica M. Alcántara-Flores ${ }^{1}$, Carlos J. Castañeda-González ${ }^{3}$ Carlos L. Aviña-Cervantes ${ }^{4}$, Petra Yescas ${ }^{5}$, María del Socorro González-Valadez ${ }^{6}$, Nancy Martínez-Rodríguez ${ }^{7}$ Antonio Ríos-Ortiz², Martha González-González, María E. López-Navarro and Patricia Rojas*

\begin{abstract}
Background: Cognitive functions represent useful endophenotypes to identify the association between genetic variants and schizophrenia. In this sense, the NR4A2 gene has been implicated in schizophrenia and cognition in different animal models and clinical trials. We hypothesized that the NR4A2 gene is associated with working memory performance in schizophrenia. This study aimed to analyze two variants and the expression levels of the NR4A2 gene with susceptibility to schizophrenia, as well as to evaluate whether possession of NR4A2 variants influence the possible correlation between gene expression and working memory performance in schizophrenia.

Methods: The current study included 187 schizophrenia patients and 227 controls genotyped for two of the most studied NR4A2 genetic variants in neurological and neuropsychiatric diseases. Genotyping was performed using High Resolution Melt and sequencing techniques. In addition, mRNA expression of NR4A2 was performed in peripheral mononuclear cells of 112 patients and 118 controls. A group of these participants, 54 patients and 87 controls, performed the working memory index of the WAIS III test.
\end{abstract}

Results: Both genotypic frequencies of the two variants and expression levels of the NR4A2 gene showed no significant difference when in patients versus controls. However, patients homozygous for the rs34884856 promoter variant showed a positive correlation between expression levels and auditory working memory.

Conclusions: Our finding suggested that changes in expression levels of the NR4A2 gene could be associated with working memory in schizophrenia depending on patients' genotype in a sample from a Mexican population.

Keywords: Schizophrenia, NR4A2 genetic variants, NR4A2 mRNA levels, Cognition, Endophenotype, Working memory

\footnotetext{
* Correspondence: prcastane@hotmail.com

${ }^{1}$ Laboratory of Neurotoxicology, Instituto Nacional de Neurología y

Neurocirugía, "Manuel Velasco Suárez", SS, Av. Insurgentes Sur No. 3877, Col.

La Fama, C.P. 14269 Mexico City, Mexico

Full list of author information is available at the end of the article
}

\section{$\triangle B M C$}

(c) The Author(s). 2021 Open Access This article is licensed under a Creative Commons Attribution 4.0 International License, which permits use, sharing, adaptation, distribution and reproduction in any medium or format, as long as you give appropriate credit to the original author(s) and the source, provide a link to the Creative Commons licence, and indicate if changes were made. The images or other third party material in this article are included in the article's Creative Commons licence, unless indicated otherwise in a credit line to the material. If material is not included in the article's Creative Commons licence and your intended use is not permitted by statutory regulation or exceeds the permitted use, you will need to obtain permission directly from the copyright holder. To view a copy of this licence, visit http://creativecommons.org/licenses/by/4.0/ The Creative Commons Public Domain Dedication waiver (http://creativecommons.org/publicdomain/zero/1.0/) applies to the data made available in this article, unless otherwise stated in a credit line to the data. 


\section{Background}

Schizophrenia is a heterogeneous, severe, and disabling mental illness that affects $1 \%$ of the world's population and is caused by interactions between environmental and genetic factors [1]. It has also considered a neurodevelopmental disorder with alterations in different neurotransmitters [2], and dopamine plays an essential role in this disease.

It is recognized by diverse symptoms, with cognitive deficits being a core feature of schizophrenia [3], and which are present in up to $98 \%$ of patients [4]. Several studies show that schizophrenia and cognitive dysfunction manifest considerable heritability between 70 to $90 \%$ and 24 to $55 \%$, respectively $[5,6]$. In particular, cognitive functions, such as working memory, have been proposed as endophenotypes related to schizophrenia [7]. An endophenotype is a subtype of biomarker, a quantitative biological trait that is thought to be related to genetic vulnerability and disease onset [8], and is characterized by being intermediate, measurable, heritable and independent traits of the disease status (present both in the prodromal stage and in patients with remission) [9].

Different genes involved in the neurodevelopment of dopaminergic neurons can be considered candidate susceptibility genes for schizophrenia and cognitive deficits $[10,11]$, for instance, the gene that codes for the nuclear receptor subfamily 4, group A (NR4A2). This transcription factor regulates the expression of genes involved in the development, survival, and phenotype of dopaminergic neurons $[12,13]$. The NR4A2 gene (also known as Nurr1) has been related to schizophrenia etiology and cognitive function [10,14-18]. Notably, in relation to this gene, Nurr1 heterozygous (+/-) mice show cognitive impairment and pharmacological responses consistent with a model for schizophrenia $[19,20]$. This correlation between NR4A2 deficiency and cognitive skills has been found in other animal models for Alzheimer's disease and attention-deficit hyperactivity disorder [18, 21] as well as its particular role in memory tasks as reported in preclinical studies [17, 22-25].

On the other hand, different clinical studies have analyzed genetic variants and gene expression levels, in peripheral blood mononuclear cells (PBMC), both as potential biomarkers for central nervous system disorders [26, 27]. In this way, several genetic variants of the NR4A2 gene have been analyzed, giving rise to nonreproducible results in different populations [28-33]. The two genetic variants analyzed in the present study have been associated with other neurological diseases, psychiatric disorders, and addiction, which are also related with dysfunction of the dopaminergic system. In particular, the rs35479735 intronic 6 variant has been associated with Parkinson's disease in Asian, Caucasian, and Mexican populations [34-36]. In addition, the rs34884856 promoter variant has been associated with alcohol dependence in people with Mexican ancestry [37].

The association between the NR4A2 gene and cognitive deficit in schizophrenia has been previously reported in a Caucasian population [32]. In that study, Ancin et al. 2013 [32] have identified an association between NR4A2 variants and cognition (sustained attention) in schizophrenia patients. In addition, preclinical studies have been shown the importance of the NR4A2 gene in cognition. Therefore, to study this association is of importance in psychiatry field, especially in schizophrenia.

Furthermore, decreased expression of the NR4A2 gene was found in the dorsolateral prefrontal cortex (DLPFC) of patients with schizophrenia [14, 38, 39]. However, the relationship of $N R 4 A 2$ expression in PBMC with gene variants in schizophrenia remains unclear. Likewise, the expression of genes related to inflammation, metabolism, and neuroprotection from PBMC have linked to alterations in the activity of brain regions [40, 41].

To our knowledge, there is a lack of studies on the relation of the NR4A2 gene with working memory deficits in schizophrenia, as well as the need to prioritize diversity in human genomics research [42] in the field of Psychiatry. Therefore, we investigate the association between the NR4A2 gene with working memory deficit in schizophrenia in the Mexican population, which is under-represented in human genomic research.

We hypothesized that the NR4A2 gene is associated with working memory performance in schizophrenia in a sample Mexican population. Therefore, this study aimed to analyze the genotype effect of two genetic variants (rs34884856 promoter variant and rs35479735 intronic 6 variant), and the expression levels of the $N R 4 A 2$ and their interactions on performance of working memory ability in schizophrenia.

The association analysis of genetic variants and levels of expression with schizophrenia was first evaluated, followed by the relationship of expression with variants, and finally the relationship of cognition with expression and variants. Thus, the interactions analyzed of working memory were diagnosis-genotype (genetic variants), genotype-expression, and diagnosis-genotype-expression.

\section{Methods \\ Participants}

This study included 187 (111 males and 76 females) patients diagnosed with schizophrenia at the Instituto Nacional de Neurología "Manuel Velasco Suárez" and Hospital Psiquiátrico Fray Bernardino Álvarez from March 2012 to December 2017. Inclusion criteria: patients confirmed by two psychiatrists, following Diagnostic and Statistical Manual of Mental Disorders Fourth 
Edition (DSM-IV) criteria [43] and the Composite International Diagnostic Interview (CIDI) Version 21 [44], and with at least 1 year of evolution. Exclusion criteria included: patients with comorbidities due to toxic substance use (except nicotine) during 3 months prior to recruitment, or other serious organic or neurological diseases.

The control volunteers consisted of 227 unrelated participants (127 males and 100 females) and recruited from March 2011 to December 2017 through announcement from population of Mexico City's metropolitan area. This group was screened by psychiatrists and completed the Mini-International Neuropsychiatric Interview (MINI) [45] to rule out any personal history of neuropsychiatric disorder. After clinical evaluation the control group was matched for age and sex with the group of cases.

Control volunteers were without history of substance abuse (except nicotine), and with no family history from of schizophrenia, or other neurological, or psychiatric disorders.

Both the patients and control group met the criteria of Mexican mestizo [46]. The analysis did not include ancestral-informative markers (AIMs). However, standard criteria were used to define the Mexican mestizo, and to keep the effects of population stratification to a minimum. According to the National Institute of Anthropology and History of Mexico, Mestizos are defined as individuals born in Mexico, having a Spanish-derived last name, with family antecedents of Mexican ancestors back at least to the third generation [47]. The study was performed in accordance with principles of the 1964 Helsinki Declaration and its later amendments. The institutional ethics committee of the Instituto Nacional de Neurología y Neurocirugía, "Manuel Velasco Suárez" and Hospital Psiquiátrico Fray Bernardino Álvarez approved the study protocol, and written informed consent was obtained from all individual participants included in the study. The experimental design is show in Fig. 1.

The 187 schizophrenia patients and 227 controls were genotyped for two of the most studied NR4A2 genetic variants in neurological and neuropsychiatric diseases (rs34884856 promoter variant and rs35479735 intronic 6 variant) (see below; Molecular analysis).

\section{Clinical and working memory evaluation}

The working memory function was evaluated in a group of patients and controls (54 patients with paranoid schizophrenia and 87 controls) of the total of participants using the Wechsler Adult Intelligence Scale (WAIS-III) standardized for the Mexican population [48]. This scale was conducted in literate patients and controls. In addition, it was also confirmed that they were not undergoing any treatment associated with drowsiness (benzodiazepine) and that they met the conditions required to obtain a correct cognitive evaluation. The severity of the schizophrenia symptoms was evaluated in the same patients by means of the Positive and Negative Syndrome Scale (PANSS) [49]. Clinical evaluation and cognitive tests (WAIS-III) were carried out between 2012 and 2017 by psychiatry and psychology experts, previously trained in the application of both tests. Because the present study aimed to evaluate working memory in schizophrenia, the subtests that evaluate this task are part of the WAIS-III. The experimental design is shown in Fig. 1.

WAIS is one of the most widely used tests to assess general intellectual ability in adults 16 years of age and older [50, 51]. From its original [52] development this test has been revised on several occasions. The WAIS-III is the fifth version of the intelligence scale and introduced four index scores derived from factor analyses of 14 subtests. The four index scores, Verbal Comprehension (VC), Perceptual Organization (PO), Working Memory (WM), and Processing Speed (PS) divide abilities into more discrete units of functioning compared to the traditional IQ scores [53].

The Working Memory Index (WMI) is commonly used to evaluate working memory ability. The WAIS-III WMI is derived from the performance on the Digit Span (DS), Arithmetic, and Letter-Number Sequencing subtests.

To evaluate the association between the NR4A2 gene and working memory in schizophrenia, WMI and its three subtests (DS, Arithmetic, and Letter-Number Sequencing) that compose it were analyzed with genetic variants and the expression levels of the NR4A2 gene. The Backward Digit Span (BDS) task, aural evaluation that is part of the DS subtest was considered for analysis. The WMI score was obtained from WAIS-III.

The DS subtest is composed of both a forward and a backward recitation condition. On the digits forward part of the subtest, the individual is verbally presented with a string of numbers and asked to repeat back the numbers in order immediately after stimuli presentation. In the digits backward condition, the individual is verbally instructed to repeat back the presented string of numbers in reverse order. The DS score combines the total number of digit strings correctly repeated in both conditions.

\section{Molecular analysis \\ DNA and RNA extraction}

The PBMC obtained from the patients were stored in stabilization solution (RNAlater, Invitrogen) at $-20^{\circ} \mathrm{C}$ until processing (DNA and RNA) to prevent the degradation of genetic material. The concentration and purity 


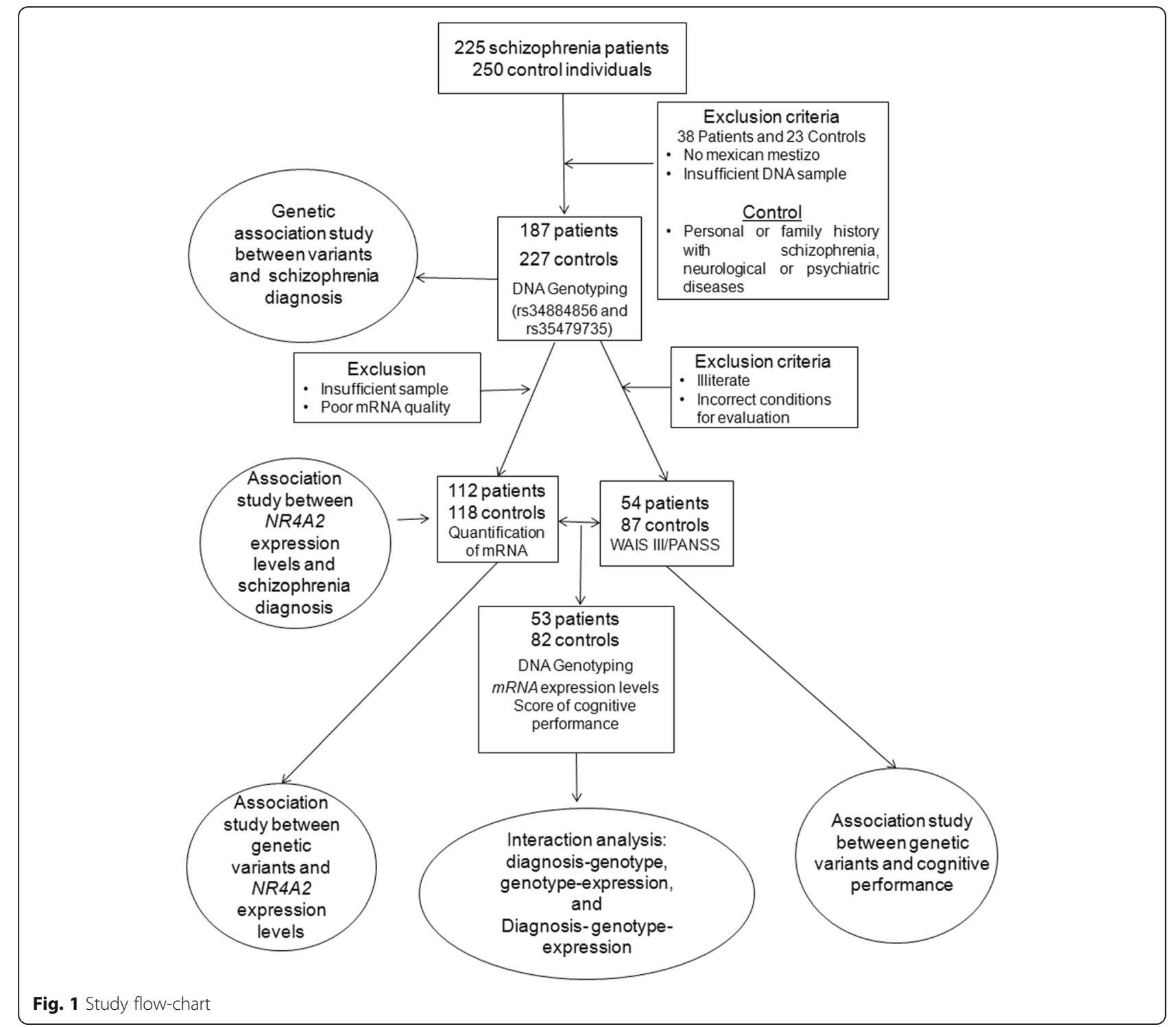

of the RNA and DNA samples were measured by spectrophotometric analysis. The integrity of the samples (DNA and RNA) was determined by horizontal electrophoresis in 1.5\% agarose / TAE $1 \mathrm{X}$ gels at $100 \mathrm{~V} / 30$ min [54]. RNA and DNA samples with a concentration greater than $50 \mathrm{ng} / \mu \mathrm{l}$, a $260 / 280$ ratio between 1.8 to 2 and with an electrophoretic pattern for high molecular weight DNA and $18 \mathrm{~s}$ and $28 \mathrm{~s}$ ribosomal RNA were chosen for the genotyping study and of genetic expression.

\section{Genotyping}

Genomic DNA was extracted from PBMC using the standard salting out procedure [55]. Two single nucleotide variants $(\mathrm{SNV})$ of NR4A2, rs35479735 in intron 6 and rs34884856 in the promoter, were genotyped in patients and the control group. Genotyping was performed using High Resolution Melt (HRM) and sequencing techniques. The oligonucleotide design and conditions of both genotyping methods have been previously described [36]. HRM analysis was performed using the Rotor-Gene 6000 instrument (Corbett Research Pty Ltd., Sydney, Australia). All analyzes were performed in triplicates.

\section{mRNA expression levels of NR4A2}

NR4A2 expression levels were evaluated in 112 patients and 118 control individuals. NR4A2 mRNA extraction was performed in PBMC by the organic technique using the TRIzol reagent, following the manufacturer's instructions. Quantification of the expression levels of the NR4A2 gene was carried out by qRT-PCR, as previously reported [36]. 
GAPDH was used as an internal reference gene to normalize target gene transcript levels. The quantitative PCR reactions were performed using predesigned primer and probes from Applied Biosystems (Foster City, CA, USA). The relative fold changes were determined by the method of $2^{-\Delta \Delta \mathrm{Ct}}$ as described previously [56]. The analysis was carried out in triplicate.

\section{Statistical analysis}

The study population is described using means and standard deviations or frequencies and percentages. Mann-Whitney $U$ tests for non-parametric data, Student $\mathrm{t}$ tests for continuous parametric data, and chi-square tests for categorical parameters were used. The HardyWeinberg equilibrium was evaluated for each variant through Pearson's chi-square. Genotype frequencies were analyzed by chi square test and the odd ratio (OR) with 95\% confidence intervals (CI) between case and control groups. A multivariate logistic regression was used with confounding variables (age, gender and educational level).

For association analysis between genotypes, gene expression and working memory, we used the recessive model considering the minor frequency allele and the risk allele described in various studies [33-37]. The recessive model postulates that the risk of the disease occurs in the homozygotes for risk allele. Therefore, genotypes were divided in two groups for each variant.

Log10- was used to transform the values of cognitive scores and gene expression levels to approximate normal distributions and to conduct an ANCOVA analysis and linear regression adjusted for age, gender, and educational level.

The association between working memory function, variant genetic and expression levels was analyzed by a two-way ANCOVA. The two fixed factors were diagnosis (schizophrenia vs control) and the genotype (recessive model). The expression levels of NR4A2 were used as a covariant, as well as demographic data including age, sex and education level. The interactions of "diagnosis $\mathrm{x}$ genotype", "genotype $\mathrm{x}$ expression" and "diagnosis $\mathrm{x}$ genotype $\mathrm{x}$ expression" were obtained. Posteriorly, whether a significant effect was identified in any interaction or main effects on the genotype, a simple effects analysis was performed in patients and controls separately. Gender, age and education (self-report of the number of years of study) were used as covariates in the simple effect analysis.

All statistical analyzes were performed using the SPSS Statistics Version 24 software (SPSS Inc., Chicago, IL, USA) and the STATA SE version 12.0 statistical software (Stata Corp, College Station, TX, USA). $p<0.05$ values were considered statistically significant. For the cognitive tests, we used Bonferroni correction for counteract the problem of multiple comparisons for the five cognitive analyzes.

The calculation of the sample size and the statistical power were performed with the software named $G$ * Power version 3.1.9.6.

\section{Results}

\section{Participant characteristics}

Demographic and clinical characteristics of patients and controls included in the study are shown in Table 1 . Gender $(p=0.485)$, education $(p=0.295)$, and age $(p=$ $0.066)$ distributions did not show any statistically significant difference between patients and control volunteers.

\section{Comparison of allele and genotype frequencies between case and control group}

The two NR4A2 genetic variants analyzed in this study have been associated with disorders related to dysfunction of dopaminergic system; their genotypic and allelic frequencies are shown in Table 1 . The rs34884856 variant on the promoter (alleles are a cytosine insertion (3C) and a deletion $\mathrm{C}$ (2C)), and rs35479735 variant in the intron 6 (a guanine insertion (3G) and a deletion G (2G)), both indels, were analyzed in the group of patients and control participants. These two variants were in Hardy-Weinberg equilibrium in both groups of participants. In particular, rs34884856 (3C) minor allele frequency (MAF) was identified in 44 and $43 \%$ of patients and control group, respectively for promoter variant. In addition, rs35479735 (2G) MAF was shown in $45 \%$ of study cases and in $46 \%$ of control individuals for the intron 6 variant. These two polymorphisms were found in strong linkage disequilibrium $\left(\mathrm{D}^{\prime}=0.87, r^{2}=0.67\right)$.

Distribution of allelic and genotypic frequencies was similar between patients and control volunteers for both variants. The bivariate logistic regression analysis for the different inheritance models was not significantly associated to schizophrenia for either variant (Supplementary 1).

\section{Comparison of NR4A2 mRNA peripheral expression between schizophrenia patients and the control group as well as with NR4A2 genetic variants}

The mRNA expression levels of NR4A2 were not significantly different between the patient and control groups $(p=0.766)$, or between the different genotypes of the two variants in patients or controls (Supplementary 2). Likewise, expression levels showed no differences by sex $(p=0.158)$, drug treatment $(p=0.224)$, or family history $(p=0.528)$ in the schizophrenia group.

\section{Analysis of the relation of schizophrenia and the rs34884856 promoter variant on cognition}

For association analysis between genotypes and working memory, we used the recessive model considering 
Table 1 Socio-demographic characteristics, clinical data, and genotype distribution of NR4A2 in schizophrenia patients and control group

\begin{tabular}{|c|c|c|c|}
\hline Characteristics & $\begin{array}{l}\text { Schizophrenia group } \\
(n=187)\end{array}$ & $\begin{array}{l}\text { Control group } \\
(n=227)\end{array}$ & $P$ \\
\hline Age, year ( \pm SD) & $35.44( \pm 10.07)$ & $38.33( \pm 13.17)$ & $0.066^{\mathrm{a}}$ \\
\hline \multicolumn{4}{|l|}{ Gender, n (\%) } \\
\hline Male & $111(59.4)$ & $127(55.9)$ & \\
\hline Female & $76(40.6)$ & $100(44.1)$ & $0.485^{b}$ \\
\hline Education, year ( $\pm S D$ ) & $10.98( \pm 3.46)$ & $11.52( \pm 4.47)$ & $0.295^{a}$ \\
\hline Family history of schizophrenia (\%) & $64(34.2)$ & - & \\
\hline Age of onset, year ( \pm SD) & $23.16( \pm 7.62)$ & - & \\
\hline Disease duration, year ( $\pm \mathrm{DS}$ ) & $12.39( \pm 9.76)$ & - & \\
\hline Typical antipsychotics, n (\%) & $64(34)$ & & \\
\hline SSRI n (\%) & $17(9)$ & & \\
\hline \multicolumn{4}{|l|}{ rs34884856 promoter variant } \\
\hline \multicolumn{4}{|l|}{ Allele n (\%) } \\
\hline $2 \mathrm{C}$ & $211(56)$ & $261(57)$ & $0.757^{b}$ \\
\hline$\underline{3 C}$ & $163(44)$ & $193(43)$ & \\
\hline \multicolumn{4}{|l|}{ Genotype n (\%) } \\
\hline $2 \mathrm{C} / 2 \mathrm{C}$ & $54(28.9)$ & $72(31.7)$ & \\
\hline $3 \mathrm{C} / 2 \mathrm{C}$ & $103(55.1)$ & $117(51.5)$ & $0.762^{b}$ \\
\hline $3 C / 3 C$ & $30(16.0)$ & $38(16.7)$ & \\
\hline HWE $(p)$ & 0.14 & 0.43 & \\
\hline \multicolumn{4}{|l|}{ rs35479735 intron 6 variant } \\
\hline \multicolumn{4}{|l|}{ Allele n (\%) } \\
\hline$\underline{2 G}$ & $168(45)$ & $211(46)$ & $0.656^{b}$ \\
\hline $3 G$ & $206(55)$ & $243(54)$ & \\
\hline \multicolumn{4}{|l|}{ Genotype n (\%) } \\
\hline $2 \mathrm{G} / 2 \mathrm{G}$ & $32(17.1)$ & $48(21.1)$ & \\
\hline $3 G / 2 G$ & $104(55.6)$ & $115(50.7)$ & $0.504^{b}$ \\
\hline $3 G / 3 G$ & $51(27.3)$ & $64(28.2)$ & \\
\hline HWE $(p)$ & 0.11 & 0.89 & \\
\hline
\end{tabular}

Data are presented as mean \pm SD. Underlined allele denotes the minor allele

$n$ Total participants, SD Standard deviation, SSRI Selective serotonin reuptake inhibitors, HWE Hardy-Weinberg Equilibrium, $3 C$ Insertion C, 2 C Deletion C, 3G Insertion G, $2 G$ Deletion

${ }^{\mathrm{a}}$ Mann Whitney $U$ test; ${ }^{\mathrm{b}} \mathrm{Chi}$-squared test

the minor frequency allele and the risk allele described in various studies [33-37]. The recessive model postulates that the risk of the disease occurs in homozygotes for the risk allele. This model is widely used in genetic association studies $[57,58]$. Therefore, genotypes were divided in two groups for the rs34884856 promoter variant: $3 \mathrm{C} / 3 \mathrm{C}$ homozygous, and $2 \mathrm{C}$ carriers ( $3 \mathrm{C} / 2 \mathrm{C}+2 \mathrm{C} / 2 \mathrm{C}$ "), for the rs35479735 intronic 6 variant: 3G/3G homozygous, and $2 \mathrm{G}$ carriers (3G/2G + 2G/2G).

The genotypes of the rs35479735 intronic 6 variant (recessive model) did not show significant differences for sociodemographic, cognitive or clinic evaluations in schizophrenia patients and the control group (Supplementary material 3).

Table 2 shows both sociodemographic and clinical variables for recessive model genotypes of the rs34884856 promoter variant. No significant differences were found between genotypes for variables such as age, gender, and education in patients and controls. Furthermore, no significant differences in clinical variables such as age of onset, family history of schizophrenia and treatment between $3 \mathrm{C} / 3 \mathrm{C}$ homozygous and carriers of the $2 \mathrm{C}$ allele were found in patients. 
Table 2 Socio-demographic and clinical characteristics of patients and the control group to the rs34884856 promoter variant

\begin{tabular}{|c|c|c|c|c|c|c|}
\hline & Schizophren & oup & & Control grou & & \\
\hline & $\begin{array}{l}3 C / 3 C \\
n=12\end{array}$ & $\begin{array}{l}3 C / 2 C+2 C / 2 C \\
n=41\end{array}$ & $p$ & $\begin{array}{l}3 C / 3 C \\
n=20\end{array}$ & $\begin{array}{l}3 C / 2 C+2 C / 2 C \\
n=62\end{array}$ & $p$ \\
\hline Age, year $( \pm S D)$ & $32.93(9.3)$ & $33.50(10.05)$ & $0.984^{\mathrm{a}}$ & $38.7(12.8)$ & $39.94(11.47)$ & $0.841^{a}$ \\
\hline Gender, n (\%) Male & $8(53.3)$ & $26(68.4)$ & $0.302^{b}$ & $10(50)$ & $30(48.4)$ & $0.900^{c}$ \\
\hline Education, year ( \pm SD) & $10.58(2.57)$ & $12.15(2.97)$ & $0.103^{\mathrm{a}}$ & $14.05(3.80)$ & $13.13(4.38)$ & $0.349^{a}$ \\
\hline Family history of schizophrenia (\%) & $5(41.7)$ & $12(29.3)$ & $0.418^{b}$ & & & \\
\hline Age of onset, year $( \pm S D)$ & $20.08(8.86)$ & $23.35(6.84)$ & $0.077^{\mathrm{a}}$ & & & \\
\hline Disease duration, year ( $\pm \mathrm{DS})$ & $11.58(8.27)$ & $10.68(9.97)$ & $0.515^{\mathrm{a}}$ & & & \\
\hline Typical antipsychotics, n (\%) & $5(33.4)$ & $14(41.7)$ & $0.284^{b}$ & & & \\
\hline SSRI n (\%) & $1(8.3)$ & $5(11.9)$ & $0.718^{b}$ & & & \\
\hline PANSS & & & & & & \\
\hline Positive symptoms & $21.00(7.50)$ & $20.45(7.98)$ & $0.994^{\mathrm{a}}$ & & & \\
\hline Negative symptoms & $26.58(9.67)$ & $21.94(7.19)$ & $0.156^{\mathrm{a}}$ & & & \\
\hline General symptoms & $41.91(14.82)$ & $37.14(10.96)$ & $0.323^{\mathrm{a}}$ & & & \\
\hline PANSS total & $88.66(28.78)$ & $79.33(22.17)$ & $0.378^{\mathrm{a}}$ & & & \\
\hline Working memory test & & & & & & \\
\hline WMI & $69.25(10.59)$ & $75.34(11.80)$ & $0.103^{\mathrm{a}}$ & $87.8(10.04)$ & $80.7(14.85)$ & $0.086^{\mathrm{a}}$ \\
\hline Arithmetic & $4.67(2.06)$ & $5.63(2.55)$ & $0.16^{a}$ & $8.65(2.30)$ & 7.69 (3.19) & $0.32^{\mathrm{a}}$ \\
\hline DS & $4.92(1.24)$ & 6.19 (2.09) & $0.033^{\mathrm{a}}$ & $6.85(2.11)$ & 6.39 (1.94) & $0.40^{a}$ \\
\hline BDS task & $2.83(1.11)$ & 4.09 (1.97) & $0.022^{\mathrm{a}}$ & $4.95(1.70)$ & $4.5(1.91)$ & $0.278^{a}$ \\
\hline LNS & $4.67(2.01)$ & $6.14(2.36)$ & $0.051^{a}$ & $8.50(1.99)$ & $6.66(3.08)$ & $0.027^{\mathrm{a}}$ \\
\hline
\end{tabular}

Data are presented as mean $\pm \mathrm{SD}$

This is a subset of the total sample submitted to cognition tasks, which had genotyping and quantification of NR42 expression levels

SD Standard deviation, $n$ Total participants, 3 C Insertion C, 2 C Deletion C, SSRI Selective serotonin reuptake inhibitors, PANSS Positive and negative syndrome scale; recessive model, $3 \mathrm{C} / 3 \mathrm{C}$ vs $3 \mathrm{C} / 2 \mathrm{C}+2 \mathrm{C} / 2 \mathrm{C}$

${ }^{a}$ Mann-Whitney $U,{ }^{b}$ Fisher test, ${ }^{c}$ Chi-squared test

Table 3 shows the ANCOVA analysis conducted for the WMI, working memory subtests (Arithmetic, DS, and Letter-Number Sequencing) and BDS task between patient and control groups according to rs 34884856 promoter variant. This analysis showed that performance scores on the BDS task, subtests and WMI were significantly lower in patients compared to healthy controls
(Table 3). Further, no genotype effect was identified for performance on any of the subtests or WMI.

\section{Working memory and expression levels of the NR4A2 gene}

We found a significant interaction effect for diagnosis (schizophrenia vs control) x genotype (recessive model,

Table 3 Comparisons among working memory test by diagnostic, genotypic groups and interaction analysis for promoter variant

\begin{tabular}{|c|c|c|c|c|c|c|c|c|c|c|c|c|}
\hline \multirow[t]{2}{*}{ Test } & \multicolumn{2}{|c|}{ Diagnosis } & \multicolumn{2}{|c|}{ Genotype } & \multicolumn{2}{|c|}{$\begin{array}{l}\text { Diagnosis } x \\
\text { genotype }\end{array}$} & \multicolumn{2}{|c|}{$\begin{array}{l}\text { Genotype } x \\
\text { expression }\end{array}$} & \multicolumn{2}{|c|}{$\begin{array}{l}\text { Diagnosis } x \text { genotype } x \\
\text { expression }\end{array}$} & \multirow[t]{2}{*}{$\begin{array}{l}\text { Statistical } \\
\text { Power }\end{array}$} & \multirow[t]{2}{*}{$\begin{array}{l}\text { Effect } \\
\text { size F }\end{array}$} \\
\hline & $F$ & $p$ & $F$ & $p$ & $F$ & $p$ & $F$ & $p$ & $\mathbf{F}$ & $p$ & & \\
\hline WMI & 9.44 & $0.003^{*}$ & 0.104 & 0.748 & 6.11 & 0.015 & 1.17 & 0.281 & 1.32 & 0.253 & 0.975 & 0.906 \\
\hline Arithmetic & 12.257 & $0.001 *$ & 0.166 & 0.685 & 2.59 & 0.110 & 1.19 & 0.276 & 0.609 & 0.437 & 0.947 & 0.852 \\
\hline DS & 5.26 & 0.024 & 2.86 & 0.093 & 3.25 & 0.074 & 2.57 & 0.111 & 0.673 & 0.413 & 0.702 & 0.668 \\
\hline BDS task & 5.01 & 0.027 & 7.48 & $0.007^{*}$ & 6.20 & 0.014 & 7.14 & $0.009 *$ & 1.719 & 0.192 & 0.772 & 0.706 \\
\hline LNS & 4.03 & 0.047 & 0.028 & 0.868 & 8.89 & $0.003^{*}$ & 0.796 & 0.374 & 2.13 & 0.147 & 0.732 & 0.684 \\
\hline
\end{tabular}

Two-way ANCOVA analysis was performed for each cognitive analysis. The two fixed factors were the genotype (recessive model) and the diagnosis (schizophrenia vs control). The expression levels NR4A2 was used as a covariant, as well as demographic data including age, sex, and education level. The interaction of diagnosis $\mathrm{x}$ genotype, genotype $\mathrm{x}$ expression and diagnosis $\mathrm{x}$ genotype $\mathrm{x}$ expression were obtained

The WMI and its three subtests (DS, Arithmetic, and LNS) that compose it were analyzed. The BDS task that is part of DS subtest was also considered for analysis. This is a subset of the total sample submitted to cognition tasks with 53 case and 82 controls, which had genotyping and quantification of NR42 expression levels WMI Working memory index, DS Total Digit Span, BDS Backward Digit Span, LNS Letter-Number Sequencing, F Test statistic for ANCOVA, $p$-value

* Bonferroni correction $<0.01$ 
"3C/3C" vs " $3 \mathrm{C} / 2 \mathrm{C}+2 \mathrm{C} / 2 \mathrm{C}$ ") on WMI $(p=0.015)$, Letter-Number Sequencing $(p=0.003)$ and BDS task (0.014), and a significant genotype $\mathrm{x}$ expression effect on the BDS task ( $p=0.009$, Bonferroni correction). Regression lineal analysis showed that BDS test was significantly correlated (simple effect $p=0.05$, beta $=0.256$ ) with expression levels NR4A2 in the patients. Also, patients homozygous for the rs34884856 promoter variant $(3 \mathrm{C} / 3 \mathrm{C})$ showed a simple effect $(p=0.022$, beta $=$ 0.76 ) between expression levels and auditory working memory (BDS) (Fig. 2). This graph shows that only in $3 C / 3 \mathrm{C}$ rs34884856 patients, a decrease of NR4A2 mRNA expression was related to BDS impairment in schizophrenia.

\section{Discussion}

It is important to mention that this is the first study to analyze the association of two genetic variants of the NR4A2 gene (rs34884856 in promoter and rs35479735 in intron 6) and NR4A2 mRNA expression with working memory deficits in schizophrenia.

\section{Genetic association study between NR4A2 variants and schizophrenia}

This study did not identify any association between the genetic variants analyzed and the schizophrenia diagnosis. Genetic association studies of NR4A2 variants with this mental disorder in different populations have produced inconclusive and controversial results [26-31, 33, 59]. This could be due to the heterogeneity of the disease diagnosis, the different populations included, and the sample sizes analyzed in different studies. The genotypic frequencies observed in our study are similar to those identified in Asian populations and different from those reported for Caucasian populations in diseases associated with dopamine dysfunction such as schizophrenia [30, 34, 35]. These two variants were found in strong linkage disequelibrium, which agrees with a study in PD of these variants in the Mexican population [36]. However, with the analyzed sample, an association with susceptibility to schizophrenia was not identified for both variables. Although no significant differences were identified by age and sex between cases and controls, other causes such as environmental factors and harmful substances, that were not measured might were influencing the lack of association.

The two genetic variants analyzed in this study have been associated in other populations with different neurological, and psychiatric disorders and addiction, which are diseases with altered dopamine function. It is important to emphasize that the differences between the populations analyzed in other studies, as well as environmental and epigenetics factors, cannot be ruled out, as well as the possibility that NR4A2 is not relevant in the susceptibility to schizophrenia. Accordingly, the study to cognitive endophenotypes in association with variants and levels of expression of the NR4A2 gene is important.

\section{Analysis of NR4A2 mRNA peripheral expression levels between schizophrenia patients and the control group as well as with NR4A2 genetic variants}

In contrast to other studies $[14,38,39]$ where a decreased mRNA expression level of NR4A2 was identified in brain tissue (DLPFC) of schizophrenia patients, our study showed no significant differences in such expression levels in the mRNA obtained from peripheral blood. It should be noted, however, that the current study analyzed a different type of biological sample (blood vs cerebral cortex tissue). It has been reported that peripheral expression of this gene was found to be significantly decreased in Parkinson's disease (PD),

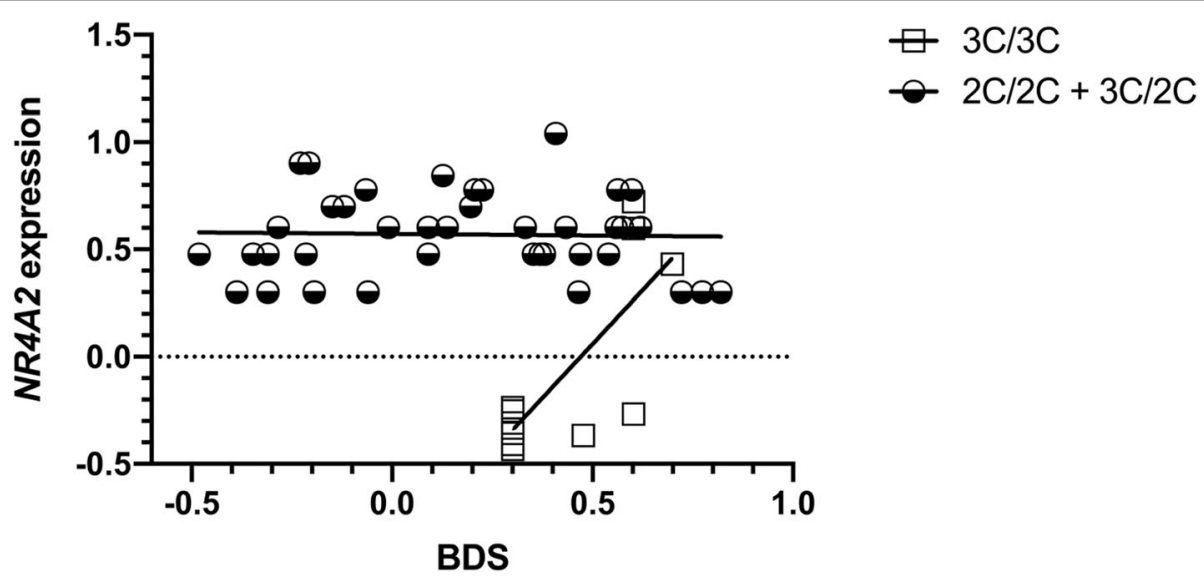

Fig. 2 Correlation between Working Memory and NR4A2 expression levels. Schizophrenia patients homozygous for 3C/3C of rs34884856 promoter variant showed a positive correlation between Backward Digit Span (BDS) and NR4A2 expression levels. In 3C/3C rs34884856 patients, a decrease of NR4A2 mRNA expression was related to working memory impairment in schizophrenia 
which is a disease associated mainly with the degeneration of dopaminergic neurons, as well as with aging in different populations [33, 36, 60, 61]. In addition, we did not find an influence of the genetic variants analyzed on the expression levels of the NR4A2 gene in schizophrenia patients as seen in PD patients [36]. In this neurodegenerative disease it has been previously reported that the levels of expression of the NR4A2 gene were decreased in $3 \mathrm{C}$ homozygous compared to the other genotypes of the rs34884856 promoter variant [36].

\section{Association between auditory working memory performance and the rs34884856 promoter variant}

Endophenotypes are a measurable and supportive tool to improve the ability to identify the association of genetic variants with clinical features, and also are the most direct expression of the effects of genes. In addition, it helps to reduce the heterogeneity of the disease phenotype by facilitating the identification of susceptibility genes. Furthermore, the use of endophenotypes is relevant for a better understanding of the pathophysiology of neuropsychiatric and neurological disorders $[9,62]$.

Working memory is one of the most widely researched cognitive functions as a cognitive endophenotype of schizophrenia given that it reflects prefrontal cortex alterations $[63,64]$. Working memory refers to the mechanisms or processes involved in the control, regulation, and keeping of relevant information active for the execution of complex cognitive tasks [65]. This cognitive function is defined as a system for both temporal storage and manipulation of information, with it participating in key cognitive processes, such as language comprehension, reading, and reasoning [66].

In the present study, an association between the rs34884856 promoter variant of the NR4A2 gene and auditory working memory in schizophrenia patients was identified. The analysis for the recessive model of this variant $(3 \mathrm{C} / 3 \mathrm{C}$ versus " $3 \mathrm{C} / 2 \mathrm{C}+2 \mathrm{C} / 2 \mathrm{C}$ ") showed significant differences in $\mathrm{BDS}$; the $3 \mathrm{C}$ homozygous patients had a lower scores compared to the $2 \mathrm{C}$ allele carriers in this task (Table 2, $p=0.022$ ). This is supported by a study that showed the association of genetic variants of this gene with sustained attention in schizophrenia patients in a Caucasian population [32]. Nevertheless, this association was not identified in the control group. However, both the genetic variants analyzed and the cognitive functions evaluated in that previously study are different from those analyzed in our study. It is noteworthy that in our study the relationship between the promoter variant and the working memory functions identified in schizophrenia patients were different from the control group for the BDS task. For the analysis of LNS, the diagnosis * genotype interaction was statistically significant. However, analysis of the single effect in patients and controls separately did not show statistically significant difference.

The difference found between patients and control group regarding the promoter variant can be related to the way in which information is received for processing, and to the affected brain regions in patients. For example, working memory subtests can be classified as verbal and nonverbal. In this context, the left side of DLPFC is more related to verbal tests and the right side of DLPFC is more related to visual spatial tests. Information input divides working memory into auditory (for instance, BDS) and visual spatial. It has been noted that the prefrontal cortex regions involved in simple information storage are different from the regions involved in actively manipulating stored information [67]. In addition, the left hemisphere shows greater pathological alterations in schizophrenia compared to the right hemisphere [68].

Our findings are consistent with studies evaluating other genetic variants that have shown these inconsistencies related to the effects of the allele between different tests and pathological conditions. One of the most widely researched variants demonstrating this effect is the BDNF genetic variant (Val66met) [69, 70]. In this case, the Met allele has a differential effect between patients and controls regarding the same cognitive function.

In addition, the importance of the NR4A2 gene in relation with metabolism and neuroprotection of dopaminergic neurons allows us to understand the association identified with cognitive endophenotypes of a working memory construct. In order to provide support for the aforementioned, various studies with genes related to dopaminergic metabolism have showed its association with cognitive endophenotypes [71].

\section{Association between cognitive functions and expression levels of the NR4A2 gene}

This is the first study to identify a positive correlation between NR4A2 gene expression levels and working memory function in schizophrenia patients. Our results are consistent with previous studies that show that the NR4A2 gene dosage is significantly related to cognitive function in animal models of schizophrenia $[19,20]$. The association of NR4A2 deficiency and reduction in performance on cognitive tasks has been reported for Alzheimer's disease and attention-deficit hyperactivity disorder animal models $[18,21]$, as well as with reports of its important role in diverse memory tasks in preclinical studies [17, 22-25]. NR4A2 is also involved in neurodevelopmental disorders and cognitive deficits as reported in clinical trials $[15,16]$.

We identified a significant positive correlation of NR4A2 mRNA expression levels with performance on 
the BDS task in $3 \mathrm{C} / 3 \mathrm{C}$ patients (rs34884856 promoter variant). The association between NR4A2 mRNA expression and better cognitive performance was found in this task of working memory.

In particular, the analysis on the BDS task demonstrated a key association when adjusting variables that affect cognition, such as age, gender, and education level. Our main result was the association of performance on the BDS with the rs34884856 promoter variant and the expression levels of the NR4A2 gene in schizophrenia patients. For instance, the BDS task allows the evaluation of alterations in auditory working memory, which is related to the left DLPFC.

Our results are consistent with the relationship between cognitive deficits in schizophrenia and dysfunction in different brain regions related to cortex, such as the DLPFC, medial prefrontal cortex, and visual cortex [64]. Therefore, a decrease in dopaminergic neurotransmission in those brain regions could be related to the cognitive deficits in this psychiatric disorder, in particular, the decrease in the NR4A2 gene in the left DLPFC (area involved in working memory, mainly auditory) in schizophrenia patients.

The first limitations of our study was the sample size for cognitive analysis. In this way, the statistical power identified in the study was borderline for DS, BDS task and LNS (0.72, 0.77, 0.73, respectively), while the effect size was medium for these analyzes. However, no significant differences concerning characteristics that could affect cognitive function were found between the different genotypic groups in either patients or controls. The current research is a pilot study that has shown the relationship of NR4A2 expression with genotype-dependent working memory. It is important to increase the sample size in future studies in order to verify this initial finding. On the other hand, this study did not analyzed AIMs. Nonetheless, various criteria were used to define the Mexican mestizo [46, 47], and to keep the effects of population stratification to a minimum. In addition, the functional effect of the rs34884856 promoter variant of the NR4A2 gene has not yet been described. Therefore, this genetic variant could be in linkage disequilibrium with another polymorphism that has a functional effect on the expression levels of this gene and thus, on cognitive function. The NR4A nuclear receptor subfamily has recently been reported to be essential regulator of neurohormonal mechanisms [72]. It could be interesting to evaluate the relationship between the expression of $N R 4 A 2$, the thyroid gland and cognition, since a low thyroid function causes a deterioration in cognition [73], as well as to study other hormones such as aldosterone. Finally, the effect of antipsychotics on cognition is not entirely clear, but there is evidence that the dose, duration, and side effects of antipsychotics may influence on cognitive function of schizophrenia patients [74]. Therefore, another limitation of the present study was that the dose of the antipsychotic treatment used by each patient was not collected, however the type of antipsychotic administered was available, and no significant differences were found between genotypes.

\section{Conclusion}

In conclusion, we identified in this study a significant effect of the relationship of the rs34884856 promoter variant and the expression levels of the NR4A2 gene on working memory endophenotypes in schizophrenia patients. Our findings suggest that decreased NR4A2 gene expression could be associated with a deficit in auditory working memory in schizophrenia patients depending on their genotype in a sample from a Mexican population.

\section{Supplementary Information}

The online version contains supplementary material available at https://doi. org/10.1186/s12888-021-03081-w.

Additional file 1: Supplementary 1. Allele frequencies and risk calculated using inheritance models. Supplementary 2. NR4A2 gene expression levels in cases and controls according to rs34884856 and rs35479735 variants. Supplementary 3. Socio-demographic and clinical characteristics of cases and controls with respect to the rs35479735 intron 6 variant.

\section{Abbreviations}

AIMs: Ancestral-informative markers; BDS: Backward Digit Span;

CIDI: Composite International Diagnostic Interview; Cl: Confidence intervals; DLPFC: Dorsolateral prefrontal cortex; DS: Total Digit Span; HRM: High Resolution Melt; MAF: Minor allele frequency; MINI: Mini-International Neuropsychiatric Interview; LNS: Letter-Number Sequencing; OR: Odd ratio; PANSS: Positive and Negative Syndrome Scale; PBMC: Peripheral blood mononuclear cells; qRT-PCR: Real-Time Quantitative Reverse Transcription Polymerase Chain reaction; SNV: Single nucleotide variants; SSRI: Selective serotonin reuptake inhibitors; WAIS-III: Wechsler Adult Intelligence Scale III; WMI: Working memory index; 3C: Insertion C; 2C: Deletion C

\section{Acknowledgements}

This work was submitted in partial fulfillment of the requirements for the PhD degree by Elizabeth Ruiz Sánchez, who is a doctoral student from the Programa de Doctorado en Ciencias Biomédicas, Universidad Nacional Autónoma de México (UNAM). We are deeply grateful to all patients and healthy controls participating in this study. The authors thank Dr. Robyn Elizabeth Hudson for her valuable comments.

\section{Authors' contributions}

ERS participated in writing and designing the protocol, participated in planning, performed genetic experiments, statistical analyses, managed the literature searches and wrote the draft and final version of the manuscript. JJG recruited participants, collected data, instructed author YMAF on protocols, supervised cognitive test, and reviewed the manuscript. YMAF participated in the organization of data collection, performed cognitive test, and reviewed the manuscript. CJCG recruited participants and revised critically the manuscript. CLAC coordinated the inclusion of patients and performed psychiatric assessment. PY participated in the collection and processing of samples and reviewed the manuscript. MSGV performed inclusion of patients and performed psychiatric assessment. NMR supervised statistical analyses and reviewed the manuscript. ARO performed psychiatric evaluation and cognitive test. MGG participated in data interpretation and contributed to final version of the manuscript. MELN performed cognitive 
test and reviewed the manuscript. PR obtained funding, conceived and designed the research, participated in writing the protocol, participated in planning, recruited participants, reviewed drafts and participated in writing the final version of the article. All authors read and approved the final manuscript.

\section{Funding}

This research was funded partially by National Council of Science and Technology of Mexico (CONACyT) grant, Project number SALUD-2008-0187095. The funders had no involvement in the preparation or writing up of this research.

\section{Availability of data and materials}

The datasets used and/or analyzed during the current study are available from the corresponding author on reasonable request.

\section{Ethics approval and consent to participate}

The institutional ethics committee of the Instituto Nacional de Neurología y Neurocirugía, "Manuel Velasco Suárez" and Hospital Psiquiátrico Fray Bernardino Álvarez approved the study protocol, and written informed consent was obtained from all individual participants included in the study. The study was performed in accordance with The Code of Ethics of the World Medical Association (Helsinki Declaration of 1964, as revised in 2018).

\section{Consent for publication}

Not applicable.

\section{Competing interests}

The authors declare that they have no competing interests.

\section{Author details}

${ }^{1}$ Laboratory of Neurotoxicology, Instituto Nacional de Neurología y Neurocirugía, "Manuel Velasco Suárez", SS, Av. Insurgentes Sur No. 3877, Col. La Fama, C.P. 14269 Mexico City, Mexico. ${ }^{2}$ Research Unit, Hospital Psiquiátrico Fray Bernardino Álvarez, Mexico City, Mexico. ${ }^{3}$ General Direction, Hospital Psiquiátrico Fray Bernardino Álvarez, Mexico City, Mexico. ${ }^{4}$ Department of Psychiatry, Instituto Nacional de Neurología y Neurocirugía, "Manuel Velasco Suárez", SS, Av. Insurgentes Sur No. 3877, Col. La Fama, C.P. 14269 Mexico City, Mexico. ${ }^{5}$ Department of Genetics, Instituto Nacional de Neurología y Neurocirugía, "Manuel Velasco Suárez", SS, Av. Insurgentes Sur No. 3877, Col. La Fama, C.P. 14269 Mexico City, Mexico. ${ }^{6}$ Health Care Division, Hospital Psiquiátrico Fray Bernardino Álvarez, Mexico City, Mexico. ${ }^{7}$ Epidemiology, Endocrinology \& Nutrition Research Unit, Hospital Infantil de México "Federico Gómez", Mexico City, Mexico. ${ }^{8}$ Unit of Cognition and Behavior, Instituto Nacional de Neurología y Neurocirugía, "Manuel Velasco Suárez", SS, Av. Insurgentes Sur No. 3877, Col. La Fama, C.P. 14269 Mexico City, Mexico.

Received: 3 August 2020 Accepted: 31 January 2021 Published online: 09 February 2021

\section{References}

1. van Os J, Rutten BP, Poulton R. Gene-environment interactions in schizophrenia: review of epidemiological findings and future directions. Schizophr Bull. 2008;34(6):1066-82. https://doi.org/10.1093/schbul/sbn117.

2. Nasrallah H, Tandon R, Keshavan M. Beyond the facts in schizophrenia: closing the gaps in diagnosis, pathophysiology, and treatment. Epidemiol Psychiatr Sci. 2011;20(4):317-27. https://doi.org/10.1017/s204579601100062x.

3. Tripathi A, Kar SK, Shukla R. Cognitive deficits in schizophrenia: understanding the biological correlates and remediation strategies. Clin Psychopharmacol Neurosci. 2018;16(1):7-17. https://doi.org/10.9758/cpn.2018.16.1.7.

4. Keefe RS, Eesley CE, Poe MP. Defining a cognitive function decrement in schizophrenia. Biol Psychiatry. 2005;57(6):688-91. https://doi.org/10.1016/j. biopsych.2005.01.003.

5. Sullivan PF, Kendler KS, Neale MC. Schizophrenia as a complex trait: evidence from a meta-analysis of twin studies. Arch Gen Psychiatry. 2003; 60(12):1187-92. https://doi.org/10.1001/archpsyc.60.12.1187.

6. Greenwood TA, Braff DL, Light GA, Cadenhead KS, Calkins ME, Dobie DJ, et al. Initial heritability analyses of endophenotypic measures for schizophrenia: the consortium on the genetics of schizophrenia. Arch Gen Psychiatry. 2007;64(11):1242-50. https://doi.org/10.1001/archpsyc.64.11.1242.
7. Luperdi SC, Tabarés-Seisdedos R, Livianos L, Vieta E, Cuesta MJ, BalanzáMartínez V. Neurocognitive endophenotypes in schizophrenia and bipolar disorder: a systematic review of longitudinal family studies. Schizophr Res. 2019;210:21-9. https://doi.org/10.1016/j.schres.2019.06.014.

8. Ross RG, Freedman R. Endophenotypes in schizophrenia for the perinatal period: criteria for validation. Schizophr Bull. 2015;41(4):824-34. https://doi. org/10.1093/schbul/sbv054.

9. Gottesman II, Gould TD. The endophenotype concept in psychiatry: etymology and strategic intentions. Am J Psychiatry. 2003;160(4):636-45. https://doi.org/10.1176/appi.ajp.160.4.636.

10. Schmidt-Kastner R, van Os J, Steinbusch HWM, Schmitz C. Gene regulation by hypoxia and the neurodevelopmental origin of schizophrenia. Schizophr Res. 2006;84(2-3):253-71. https://doi.org/10.1016/j.schres.2006.02.022.

11. Birnbaum $R$, Weinberger DR. Genetic insights into the neurodevelopmental origins of schizophrenia. Nat Rev Neurosci. 2017;18(12):727-40. https://doi. org/10.1038/nrn.2017.125.

12. Smits SM, Ponnio T, Conneely OM, Burbach JP, Smidt MP. Involvement of Nurr1 in specifying the neurotransmitter identity of ventral midbrain dopaminergic neurons. Eur J Neurosci. 2003;18(7):1731-8. https://doi.org/1 0.1046/j.1460-9568.2003.02885.x.

13. Eells JB, Wilcots J, Sisk S, Guo-Ross SX. NR4A gene expression is dynamically regulated in the ventral tegmental area dopamine neurons and is related to expression of dopamine neurotransmission genes. J Mol Neurosci. 2012; 46(3):545-53. https://doi.org/10.1007/s12031-011-9642-z.

14. Corley SM, Tsai SY, Wilkins MR, Shannon Weickert C. Transcriptomic analysis shows decreased cortical expression of NR4A1, NR4A2 and RXRB in schizophrenia and provides evidence for nuclear receptor dysregulation. PLoS One. 2016;11(12):e0166944. https://doi.org/10.1371/journal.pone.0166944.

15. Reuter MS, Krumbiegel M, Schlüter $G$, Ekici $A B$, Reis $A$, Zweier $C$. Haploinsufficiency of NR4A2 is associated with a neurodevelopmental phenotype with prominent language impairment. Am J Med Genet A. 2017 173(8):2231-4. https://doi.org/10.1002/ajmg.a.38288.

16. Lévy J, Grotto S, Mignot C, Maruani A, Delahaye-Duriez A, Benzacken B, et al. NR4A2 haploinsufficiency is associated with intellectual disability and autism spectrum disorder. Clin Genet. 2018;94(2):264-8. https:/doi.org/10.1111/cge.13383.

17. Kwapis JL, Alaghband Y, López AJ, Long JM, Li X, Shu G, et al. HDAC3mediated repression of the $\mathrm{Nr} 4 \mathrm{a}$ family contributes to age-related impairments in long-term memory. J Neurosci. 2019;39(25):4999-5009. https://doi.org/10.1523/JNEUROSCI.2799-18.2019.

18. Moon M, Jung ES, Jeon SG, Cha MY, Jang Y, Kim W, et al. Nurr1 (NR4A2) regulates Alzheimer's disease-related pathogenesis and cognitive function in the 5XFAD mouse model. Aging Cell. 2019;18(1):e12866. https://doi.org/1 $0.1111 /$ acel. 12866

19. Rojas P, Joodmardi E, Hong Y, Perlmann T, Ogren SO. Adult mice with reduced Nurr1 expression: an animal model for schizophrenia. Mol Psychiatry. 2007;12(8):756-66. https://doi.org/10.1038/sj.mp.4001993.

20. Vuillermot S, Joodmardi E, Perlmann T, Ögren SO, Feldon J, Meyer U. Schizophrenia-relevant behaviors in a genetic mouse model of constitutive Nurr1 deficiency. Genes Brain Behav. 2011;10(5):589-603. https://doi.org/1 0.1111/j.1601-183X.2011.00698.x.

21. Montarolo F, Martire S, Perga S, Spadaro M, Brescia I, Allegra S, et al. NURR1 deficiency is associated to ADHD-like phenotypes in mice. Transl Psychiatry. 2019:9(1):207. https://doi.org/10.1038/s41398-019-0544-0.

22. Colón-Cesario Wl, Martínez-Montemayor MM, Morales S, Félix J, Cruz J, Adorno $M$, et al. Knockdown of Nurr1 in the rat hippocampus: implications to spatial discrimination learning and memory. Learn Mem. 2006;13(6):734-44. https://doi.org/10.1101//m.407706.

23. Hawk JD, Abel T. The role of NR4A transcription factors in memory formation. Brain Res Bull. 2011;85(1-2):21-9. https://doi.org/10.1016/j.bra inresbull.2011.02.001.

24. Kim Jl, Jeon SG, Kim KA, Kim YJ, Song EJ, Choi J, et al. The pharmacological stimulation of Nurr1 improves cognitive functions via enhancement of adult hippocampal neurogenesis. Stem Cell Res. 2016;17(3):534-43. https://doi. org/10.1016/j.scr.2016.09.027.

25. McNulty SE, Barrett RM, Vogel-Ciernia A, Malvaez M, Hernandez N, Davatolhagh MF, et al. Differential roles for Nr4a1 and Nr4a2 in object location vs. object recognition long-term memory. Learn Mem. 2012;19(12): 588-92. https://doi.org/10.1101//m.026385.112.

26. Lai CY, Scarr E, Udawela M, Everall I, Chen WJ, Dean B. Biomarkers in schizophrenia: a focus on blood based diagnostics and theranostics. World J Psychiatry. 2016;6(1):102-17. https://doi.org/10.5498/wjp.v6.i1.102. 
27. Perkovic MN, Erjavec GN, Strac DS, Uzun S, Kozumplik O, Pivac N. Theranostic biomarkers for schizophrenia. Int J Mol Sci. 2017;18(4):733. https://doi.org/10.3390/ijms18040733.

28. Chen YH, Tsai MT, Shaw CK, Chen $\mathrm{CH}$. Mutation analysis of the human NR4A2 gene, an essential gene for midbrain dopaminergic neurogenesis, in schizophrenic patients. Am J Med Genet. 2001;105(8):753-7. https://doi. org/10.1002/ajmg.10036.

29. Ishiguro H, Okubo Y, Ohtsuki T, Yamakawa-Kobayashi K, Arinami T. Mutation analysis of the retinoid $X$ receptor beta, nuclear-related receptor 1 , and peroxisome proliferator-activated receptor alpha genes in schizophrenia and alcohol dependence: possible haplotype association of nuclear-related receptor 1 gene to alcohol dependence. Am J Med Genet. 2002;114(1):1523. https://doi.org/10.1002/ajmg.1620.

30. Carmine A, Buervenich S, Galter D, Jönsson EG, Sedvall GC, Farde L, et al NURR1 promoter polymorphisms: Parkinson's disease, schizophrenia, and personality traits. Am J Med Genet B Neuropsychiatr Genet. 2003;120B(1): 51-7. https://doi.org/10.1002/ajmg.b.20033.

31. Iwayama-Shigeno $Y$, Yamada K, Toyota T, Shimizu H, Hattori $E$, Yoshitsugu K, et al. Distribution of haplotypes derived from three common variants of the NR4A2 gene in Japanese patients with schizophrenia. Am J Med Genet B Neuropsychiatr Genet. 2003;118B(1): 20-4. https://doi.org/10.1002/ajmg.b.10053.

32. Ancín I, Cabranes JA, Vázquez-Álvarez B, Santos JL, Sánchez-Morla E, Alaerts $M$, et al. NR4A2: effects of an "orphan" receptor on sustained attention in a schizophrenic population. Schizophr Bull. 2013;39(3):555-63. https://doi. org/10.1093/schbul/sbr176.

33. Liu H, Fu Y, Ren J, Yu S, Liu H, Jiang P, et al. Association between NR4A2 genetic variation and schizophrenia: a comprehensive systematic review and meta-analysis. Neurosci Lett. 2015;598:85-90. https://doi.org/10.1016/j. neulet.2015.05.018.

34. Zheng K, Heydari B, Simon DK. A common NURR1 polymorphism associated with Parkinson disease and diffuse Lewy body disease. Arch Neurol. 2003;60(5):722-5. https://doi.org/10.1001/archneur.60.5.722.

35. Liu H, Liu H, Li T, Cui J, Fu Y, Ren J, et al. NR4A2 genetic variation and Parkinson's disease: evidence from a systematic review and meta-analysis. Neurosci Lett. 2017;650:25-32. https://doi.org/10.1016/j.neulet.2017.01.062.

36. Ruiz-Sánchez E, Yescas P, Rodríguez-Violante M, Martínez-Rodríguez N, DíazLópez JN, Ochoa A, et al. Association of polymorphisms and reduced expression levels of the NR4A2 gene with Parkinson's disease in a Mexican population. J Neurol Sci. 2017;379:58-63. https://doi.org/10.101 6/j.jns.2017.05.029

37. Wei YM, Du YL, Nie YQ, Li YY, Wan YJ. Nur-related receptor 1 gene polymorphisms and alcohol dependence in Mexican Americans. World J Gastroenterol. 2012;18(37):5276-82. https://doi.org/10.3748/wjg.v18.i37.5276.

38. Xing G, Zhang $L$, Russell S, Post R. Reduction of dopamine-related transcription factors Nurr1 and NGFI-B in the prefrontal cortex in schizophrenia and bipolar disorders. Schizophr Res. 2006;84(1):36-56. https://doi.org/10.1016/j.schres.2005.11.006.

39. Guillozet-Bongaarts AL, Hyde TM, Dalley RA, Hawrylycz MJ, Henry A, Hof PR, et al. Altered gene expression in the dorsolateral prefrontal cortex of individuals with schizophrenia. Mol Psychiatry. 2014;19(4):478-85. https://doi. org/10.1038/mp.2013.30.

40. Wu JQ, Green MJ, Gardiner EJ, Tooney PA, Scott RJ, Carr VJ, et al. Altered neural signaling and immune pathways in peripheral blood mononuclear cells of schizophrenia patients with cognitive impairment: a transcriptome analysis. Brain Behav Immun. 2016;53:194-206. https://doi.org/10.1016/j.bbi.2015.12.010.

41. Ibrahim EC, Guillemot V, Comte M, Tenenhaus A, Zendjidjian XY, Cancel A, et al. Modeling a linkage between blood transcriptional expression and activity in brain regions to infer the phenotype of schizophrenia patients. NPJ Schizophr. 2017;3(1):25. https://doi.org/10.1038/s41537-017-0027-3.

42. Hindorff LA, Bonham VL, Brody LC, Ginoza MEC, Hutter CM, Manolio TA, et al. Prioritizing diversity in human genomics research. Nat Rev Genet. 2018;19(3):175-85. https://doi.org/10.1038/nrg.2017.89.

43. American Psychiatric Association. Diagnostic and statistical manual of mental disorders (4 $4^{\text {th }}$ ed., text rev.; DSM-IV-R). Washington, D.C: American Psychiatric Association; 2000.

44. Kessler RC, Ustün TB. The World Mental Health (WMH) survey initiative version of the World Health Organization (WHO) composite international diagnostic interview (CIDI). Int J Methods Psychiatr Res. 2004;13(2):93-121. https://doi.org/10.1002/mpr.168.
45. Sheehan DV, Lecrubier Y, Sheehan KH, Amorim P, Janavs J, Weiller E, et al. The Mini-International Neuropsychiatric Interview (M.I.N.I.): the development and validation of a structured diagnostic psychiatric interview for DSM-IV and ICD-10. J Clin Psychiatry. 1998;59(Suppl 20):22-33.

46. Gamboa R, Hernandez-Pacheco G, Hesiquio R, Zuñiga J, Massó F, Montaño LF, Ramos-Kuri M, Estrada J, Granados J, Vargas-Alarcón G. Apolipoprotein E polymorphism in the Indian and mestizo populations of Mexico. Hum Biol. 2000;72(6):975-81.

47. Sánchez-Serrano C. Mestizaje e historia de la población en México (con un esbozo antropológico de los lacandones de Chiapas). In: Martín MÁ, García $B P$, editors. Polimorfismo génico (HLA) en poblaciones Hispanoamericanas. Madrid: Real Academia de Ciencias Exactas, Físicas y Naturales; 1996.

48. Tulsky D, Zhu J. Escala Wechsler de Inteligencia para adultos-III. Mexico City: El manual Moderno; 2003.

49. Kay SR, Fiszbein A, Opler LA. The positive and negative syndrome scale (PANSS) for schizophrenia. Schizophr Bull. 1987;13(2):261-76. https://doi. org/10.1093/schbul/13.2.261.

50. Camara WJ, Nathan JS, Puente A. Psychological test usage: implications in professional psychology. Prof Psychol Res Pract. 2000;31(2):141-54. https:// doi.org/10.1037/0735-7028.31.2.141.

51. Rabin LA, Barr WB, Burton LA. Assessment practices of clinical neuropsychologists in the United States and Canada: a survey of INS, NAN, and APA Division 40 members. Arch Clin Neuropsychol. 2005;20:33-65. https://doi.org/10.1016/j.acn.2004.02.005.

52. Wechsler $\mathrm{D}$. The measurement of adult intelligence. 3rd ed. Baltimore: The Williams \& Wilkins Company; 1944.

53. Wechsler D. WAIS-III WMS-III technical manual. San Antonio: The Psychological Corporation; 2002.

54. Lee PY, Costumbrado J, Hsu CY, Kim YH. Agarose gel electrophoresis for the separation of DNA fragments. J Vis Exp. 2012;62:3923. https://doi.org/10.3 791/3923.

55. Chacon-Cortes D, Haupt LM, Lea RA, Griffiths LR. Comparison of genomic DNA extraction techniques from whole blood samples: a time, cost and quality evaluation study. Mol Biol Rep. 2012;39(5):5961-6. https://doi.org/1 0.1007/s11033-011-1408-8.

56. Livak KJ, Schmittgen TD. Analysis of relative gene expression data using real-time quantitative PCR and the 2(-Delta Delta C(T)) method. Methods. 2001:402-8. https://doi.org/10.1006/meth.2001.1262.

57. Iniesta R, Guinó E, Moreno V. Análisis estadístico de polimorfismos genéticos en estudios epidemiológicos [Statistical analysis of genetic polymorphisms in epidemiological studies]. Gac Sanit. 2005;19(4):333-41. https://doi.org/1 $0.1157 / 13078029$

58. Langefeld CD, Fingerlin TE. Association methods in human genetics. Methods Mol Biol. 2007:404:431-60. https://doi.org/10.1007/978-1-59745-53 $0-5 \_21$.

59. Ruano D, Macedo A, Dourado A, Soares MJ, Valente J, Coelho I, et al. NR4A2 and schizophrenia: lack of association in a Portuguese/Brazilian study. Am J Med Genet B Neuropsychiatr Genet. 2004;128B(1):41-5. https://doi.org/10.1 002/ajmg.b.30031.

60. Le W, Pan T, Huang M, Xu P, Xie W, Zhu W, et al. Decreased NURR1 gene expression in patients with Parkinson's disease. J Neurol Sci. 2008;273(1-2): 29-33. https://doi.org/10.1016/j.jns.2008.06.007.

61. Montarolo F, Perga S, Martire S, Navone DN, Marchet A, Leotta D, et al. Altered NR4A subfamily gene expression level in peripheral blood of Parkinson's and Alzheimer's disease patients. Neurotox Res. 2016;30(3):33844. https://doi.org/10.1007/s12640-016-9626-4.

62. Goodman M, New AS, Triebwasser J, Collins KA, Siever L. Phenotype, endophenotype, and genotype comparisons between borderline personality disorder and major depressive disorder. J Personal Disord. 2010; 24(1):38-59. https://doi.org/10.1521/pedi.2010.24.1.38.

63. Park S, Gooding DC. Working memory impairment as an endophenotypic marker of a schizophrenia diathesis. Schizophr Res Cogn. 2014;1(3):127-36. https://doi.org/10.1016/j.scog.2014.09.005.

64. Braff DL. The importance of endophenotypes in schizophrenia research. Schizophr Res. 2015;163(1-3):1-8. https://doi.org/10.1016/j.schres.2015. 02.007.

65. Miyake A, Shah P. Models of working memory: mechanisms of active maintenance and executive control. New York: Cambridge University Press; 1999. https://doi.org/10.1017/CBO9781139174909.

66. Tirapu-Ustárroz J, Muñoz-Céspedes JM. Memoria y funciones ejecutivas [Memory and the executive functions]. Rev Neurol. 2005;41(8):475-84. 
67. Tsukiura T, Fujii T, Takahashi T, Xiao R, Inase M, lijima T, et al. Neuroanatomical discrimination between manipulating and maintaining processes involved in verbal working memory; a functional MRI study. Brain Res Cogn Brain Res. 2001;11(1):13-21. https://doi.org/10.1016/s0926-641 0(00)00059-8.

68. Angrilli A, Spironelli C, Elbert T, Crow TJ, Marano G, Stegagno L. Schizophrenia as failure of left hemispheric dominance for the phonological component of language. PLoS One. 2009;4(2):e4507. https://doi.org/10.1371/ journal.pone.0004507.

69. Shen T, You Y, Joseph C, Mirzaei M, Klistorner A, Graham SL, et al. BDNF polymorphism: a review of its diagnostic and clinical relevance in neurodegenerative disorders. Aging Dis. 2018;9(3):523-36. https://doi.org/1 $0.14336 / A D .2017 .0717$

70. Tsai SJ. Critical issues in BDNF Val66Met genetic studies of neuropsychiatric disorders. Front Mol Neurosci. 2018;11:156. https://doi.org/10.3389/fnmol.2 018.00156 .

71. Zai G, Robbins TW, Sahakian BJ, Kennedy JL. A review of molecular genetic studies of neurocognitive deficits in schizophrenia. Neurosci Biobehav Rev. 2017;72:50-67. https://doi.org/10.1016/j.neubiorev.2016.10.024.

72. Medzikovic L, de Vries CJM, de Waard V. NR4A nuclear receptors in cardiac remodeling and neurohormonal regulation. Trends Cardiovasc Med. 2019; 29(8):429-37. https://doi.org/10.1016/j.tcm.2018.11.015.

73. Bavarsad K, Hosseini M, Hadjzadeh MA, Sahebkar A. The effects of thyroid hormones on memory impairment and Alzheimer's disease. J Cell Physiol. 2019. https://doi.org/10.1002/jcp.28198.

74. MacKenzie NE, Kowalchuk C, Agarwal SM, Costa-Dookhan KA, Caravaggio F, Gerretsen P, Chintoh A, Remington GJ, Taylor VH, Müeller DJ, Graff-Guerrero A, Hahn MK. Antipsychotics, metabolic adverse effects, and cognitive function in schizophrenia. Front Psychiatry. 2018;9:622. https://doi.org/10.33 89/fpsyt.2018.00622.

\section{Publisher's Note}

Springer Nature remains neutral with regard to jurisdictional claims in published maps and institutional affiliations.

Ready to submit your research? Choose BMC and benefit from:

- fast, convenient online submission

- thorough peer review by experienced researchers in your field

- rapid publication on acceptance

- support for research data, including large and complex data types

- gold Open Access which fosters wider collaboration and increased citations

- maximum visibility for your research: over $100 \mathrm{M}$ website views per year

At $\mathrm{BMC}$, research is always in progress.

Learn more biomedcentral.com/submissions 